ARTICLE

Received 6 Dec 2012 | Accepted 8 Mar 2013 | Published 16 Apr 2013 DOl: 10.1038/ncomms2729

\title{
Codoping titanium dioxide nanowires with tungsten and carbon for enhanced photoelectrochemical performance
}

In Sun Cho', Chi Hwan Lee, Yunzhe Feng², Manca Logar², Pratap M. Rao', Lili Cai', Dong Rip Kim³, Robert Sinclair ${ }^{2} \&$ Xiaolin Zheng $^{1}$

Recent density-functional theory calculations suggest that codoping $\mathrm{TiO}_{2}$ with donoracceptor pairs is more effective than monodoping for improving photoelectrochemical water-splitting performance because codoping can reduce charge recombination, improve material quality, enhance light absorption and increase solubility limits of dopants. Here we report a novel ex-situ method to codope $\mathrm{TiO}_{2}$ with tungsten and carbon ( $\mathrm{W}, \mathrm{C}$ ) by sequentially annealing $\mathrm{W}$-precursor-coated $\mathrm{TiO}_{2}$ nanowires in flame and carbon monoxide gas. The unique advantages of flame annealing are that the high temperature $\left(>1,000{ }^{\circ} \mathrm{C}\right)$ and fast heating rate of flame enable rapid diffusion of $\mathrm{W}$ into $\mathrm{TiO}_{2}$ without damaging the nanowire morphology and crystallinity. This is the first experimental demonstration that codoped $\mathrm{TiO}_{2}:(\mathrm{W}, \mathrm{C})$ nanowires outperform monodoped $\mathrm{TiO}_{2}: \mathrm{W}$ and $\mathrm{TiO}_{2}: \mathrm{C}$ and double the saturation photocurrent of undoped $\mathrm{TiO}_{2}$ for photoelectrochemical water splitting. Such significant performance enhancement originates from a greatly improved electrical conductivity and activity for oxygen-evolution reaction due to the synergistic effects of codoping.

\footnotetext{
${ }^{1}$ Department of Mechanical Engineering, Stanford University, Stanford, California 94305, USA. ${ }^{2}$ Department of Materials Science and Engineering, Stanford University, Stanford, California 94305, USA. ${ }^{3}$ Department of Mechanical Engineering, Hanyang University, Seoul 133-791, South Korea. Correspondence and requests for materials should be addressed to X.Z. (email: xlzheng@stanford.edu)
} 
T $\mathrm{iO}_{2}$ has been extensively investigated as a photoanode for photoelectrochemical (PEC) water splitting owing to its high photocatalytic activity, proper band-edge positions, superior photo-chemical stability, low-cost and non-toxicity ${ }^{1-7}$. Much research effort has been devoted to combat the large band gap of $\mathrm{TiO}_{2}(\sim 3.0-3.2 \mathrm{eV})^{8,9}$ by using cationic ${ }^{10}$ or anionic doping (or alloying, especially for high doping concentration) ${ }^{11-13}$. Although monodoping (single element doping) reduces the band gap of $\mathrm{TiO}_{2}$ to some extent, it increases charge carrier recombination ${ }^{10,14}$ and eventually decreases the overall PEC performance. Even without doping, the performance of $\mathrm{TiO}_{2^{-}}$ based PEC water-splitting cells is greatly limited by its rapid charge recombination due to the high trap densities in $\mathrm{TiO}_{2}{ }_{2}^{4}$.

Recently, a new donor-acceptor codoping concept was proposed to improve the PEC water-splitting performance of $\mathrm{TiO}_{2}$ photoanode because codoping $\mathrm{TiO}_{2}$ with donor-acceptor pairs can reduce charged defects and their associated recombination, improve material quality, enhance light absorption and increase solubility limits of dopants ${ }^{15-19}$. According to densityfunctional theory calculations, various donor-accepter pairs, such as $(\mathrm{W}, \mathrm{C})^{15,19},(\mathrm{Mo}, \mathrm{C})^{15,16,19},(2 \mathrm{Nb}, \mathrm{C})^{15,18},(2 \mathrm{Ta}, \mathrm{C})^{15,18},(\mathrm{~W}$, $2 \mathrm{~N})^{15,20},(\mathrm{Ta}, \mathrm{N})^{15},(\mathrm{Nb}, \mathrm{N})^{15},(\mathrm{Sb}, \mathrm{N})^{21},(\mathrm{Cr}, \mathrm{N})^{22},(\mathrm{Zr}, \mathrm{S})^{15}$ and $(\mathrm{Nb}, \mathrm{P})^{15}$, have been proposed as good candidates for $\mathrm{TiO}_{2}$ codoping on the basis of the modified band gaps and band-edge positions. Nevertheless, up to date, there is only indirect experimental evidence for the effects of codoping for PEC water splitting. For example, a number of metal/anion codoping pairs were shown to improve the photocatalytic activities of $\mathrm{TiO}_{2}$ for organic pollutant decomposition due to enhanced visible-light absorption and charge separation ${ }^{22-27}$. Codoping $\mathrm{ZnO}$ with (Ga, $\mathrm{N}$ ) led to highly conductive p-type $\mathrm{ZnO}$ film ${ }^{28}$, and improved PEC performance because of enhanced visible-light absorption and crystallinity ${ }^{29}$. Codoping $\mathrm{LiFePO}_{4}$ with $(\mathrm{Si}, \mathrm{F})$ showed enhanced electrical conductivity and thus led to improved cathode rate performance for Li-ion batteries. ${ }^{30}$

To our best knowledge, there is no direct experimental demonstration on the effect of codoping $\mathrm{TiO}_{2}$ for PEC application because of the lack of suitable doping methods for donor (metallic) dopants. Previous methods of doping $\mathrm{TiO}_{2}$ with metallic donors typically introduced the dopants during the synthesis stage of $\mathrm{TiO}_{2}$ with methods, such as sol-gel $23,26,31$, hydrothermal $^{32}$, sputtering ${ }^{27}$ and solution combustion ${ }^{33}$. All these in-situ doping methods change the crystallinity/morphology compared with undoped $\mathrm{TiO}_{2}$, preventing the isolation of the doping effect from crystallinity/morphology effects on the PEC performance. Here we report a novel ex-situ sol-flame doping method to dope $\mathrm{TiO}_{2}$ nanowires (NWs) with metallic dopants (donor), and $\mathrm{C}$ (acceptor) is subsequently doped into $\mathrm{TiO}_{2}$ by conventional carbon monoxide $(\mathrm{CO})$ annealing. The $\mathrm{TiO}_{2}$ : $(\mathrm{W}, \mathrm{C})$ NWs double the saturation water oxidation photocurrent of undoped $\mathrm{TiO}_{2}$ for PEC water splitting and outperform the monodoped samples $\left(\mathrm{TiO}_{2}: \mathrm{W}\right.$ and $\left.\mathrm{TiO}_{2}: \mathrm{C}\right)$. Moreover, such significant $\mathrm{PEC}$ enhancement is because the codoping $\mathrm{TiO}_{2}$ with (W, C) significantly improves the electrical conductivity of $\mathrm{TiO}_{2}$ and modestly enhances its activity for oxygen-evolution reaction (OER) as well.

\section{Results}

Ex-situ codoping of $\mathrm{TiO}_{2} \mathrm{NWs}$. The ex-situ codoping method for $\mathrm{TiO}_{2} \mathrm{NWs}$ is illustrated in Fig. 1. First, rutile $\mathrm{TiO}_{2} \mathrm{NWs}$ with an average length of $2.8 \mu \mathrm{m}$ and diameter of $100 \mathrm{~nm}$ are grown on fluorine-doped tin oxide (FTO) glass substrates by the hydrothermal method ${ }^{34}$, and the $\mathrm{W}$-dopant precursor solution is prepared separately by the sol-gel method (see Methods section). Second, the $\mathrm{TiO}_{2} \mathrm{NWs}$ are dip-coated with the W-precursor solution $(0.05 \mathrm{M})$ and then dried by air blowing, which leaves a uniform thin layer of $\mathrm{W}$ precursor on the surface of $\mathrm{TiO}_{2} \mathrm{NWs}$. Next, the $\mathrm{W}$-precursor-coated $\mathrm{TiO}_{2} \mathrm{NWs}$ are annealed in a $1,100^{\circ} \mathrm{C}$ flame for $2 \mathrm{~min}$ that promotes the rapid diffusion of $\mathrm{W}$ into $\mathrm{TiO}_{2} \mathrm{NWs}$. Finally, the $\mathrm{W}$-doped $\mathrm{TiO}_{2} \mathrm{NWs}$ are annealed in gaseous $\mathrm{CO}$ at $550^{\circ} \mathrm{C}$ for $30 \mathrm{~min}$ in a tube furnace. As such, $\mathrm{TiO}_{2}$ NWs are successfully doped with the (W, C) donor-acceptor pair.

Our ex-situ sequential doping method has several advantages. First, the most unique aspect of our doping method is the combination of sol-gel process and flame annealing (named as sol-flame) for doping W. Flame provides high temperature and an ultrafast heating rate to enable rapid dopant diffusion occurring in a very short time (a couple of minutes or less). Such brief high-temperature annealing minimizes morphology and crystallinity change of $\mathrm{TiO}_{2}$ NWs. The flame-annealed $\mathrm{TiO}_{2}: \mathrm{W}$ NWs have almost identical morphology (Supplementary Fig. S1a,b) and crystallinity (Supplementary Fig. S1e,f) with that of as-synthesized (undoped) $\mathrm{TiO}_{2} \mathrm{NWs}$. When the W-precursorcoated $\mathrm{TiO}_{2} \mathrm{NWs}$ are annealed in a conventional furnace, the slow heating rate of the furnace limits the annealing temperature to be not more than $600{ }^{\circ} \mathrm{C}$ to protect the FTO substrates. As a result, $\mathrm{WO}_{3-x}$ particles are formed on the surface of $\mathrm{TiO}_{2} \mathrm{NWs}$ instead of diffusing into $\mathrm{TiO}_{2}$ (Supplementary Fig. S1c). Furthermore, even with rapid thermal annealing at $1,100^{\circ} \mathrm{C}$ using the furnace (that is, preheating the furnace to $1,100^{\circ} \mathrm{C}$ first and then quickly inserting the sample), cracks are generated in glass substrate due to thermal stress (Supplementary Fig. S1d), showing the advantage of flame annealing. Second, the ex-situ doping approach, that is, incorporating dopants after NW growth, can be broadly applied to various metal-oxide NWs regardless of their synthesis methods. Third, the sequential doping process enables independent control and optimization of doping conditions for each dopant (Supplementary Fig. S2). It should be noted that our doping methods are applicable to other donor-accepter pairs as well. We have tested other codoping pairs, including $(\mathrm{Nb}, \mathrm{C})$ and $(\mathrm{Ta}, \mathrm{C})$, and they also exhibit better PEC performance than the $\mathrm{Nb}$, $\mathrm{Ta}$ or $\mathrm{C}$ monodoped $\mathrm{TiO}_{2}$ and undoped $\mathrm{TiO}_{2}$ (Supplementary Fig. S3).

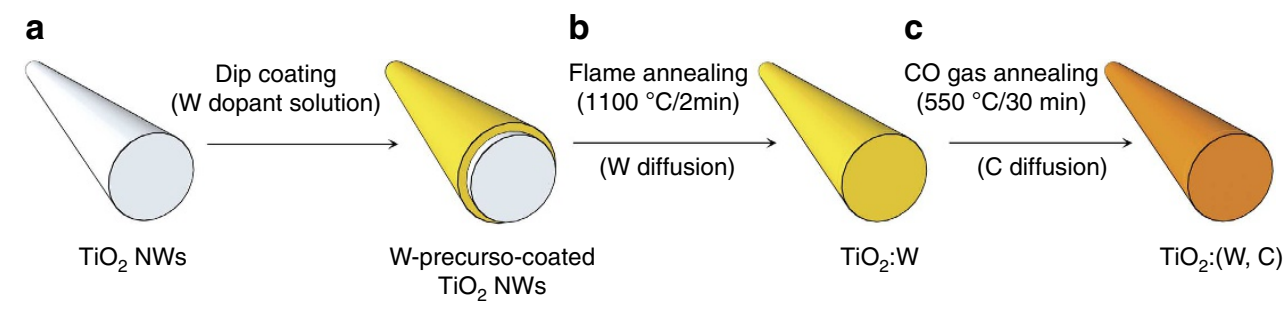

Figure 1 | Schematic illustration of the ex-situ doping method. (a) The as-synthesized $\mathrm{TiO}_{2} \mathrm{NWs}$ grown by the hydrothermal method are dip-coated with $\mathrm{W}$-precursor solution and then dried by air (or $\mathrm{N}_{2}$ ) blowing. (b) The W-precursor-coated NWs are annealed in a high-temperature flame $\left(1,100{ }^{\circ} \mathrm{C}\right.$ for $2 \mathrm{~min}$ ) to enable rapid $\mathrm{W}$ diffusion. (c) The $\mathrm{W}$-doped $\mathrm{TiO}_{2} \mathrm{NWs}$ are annealed in a tube furnace at $550^{\circ} \mathrm{C}$ for 30 min under $\mathrm{CO}$ gas flow for $\mathrm{C}$ doping. 

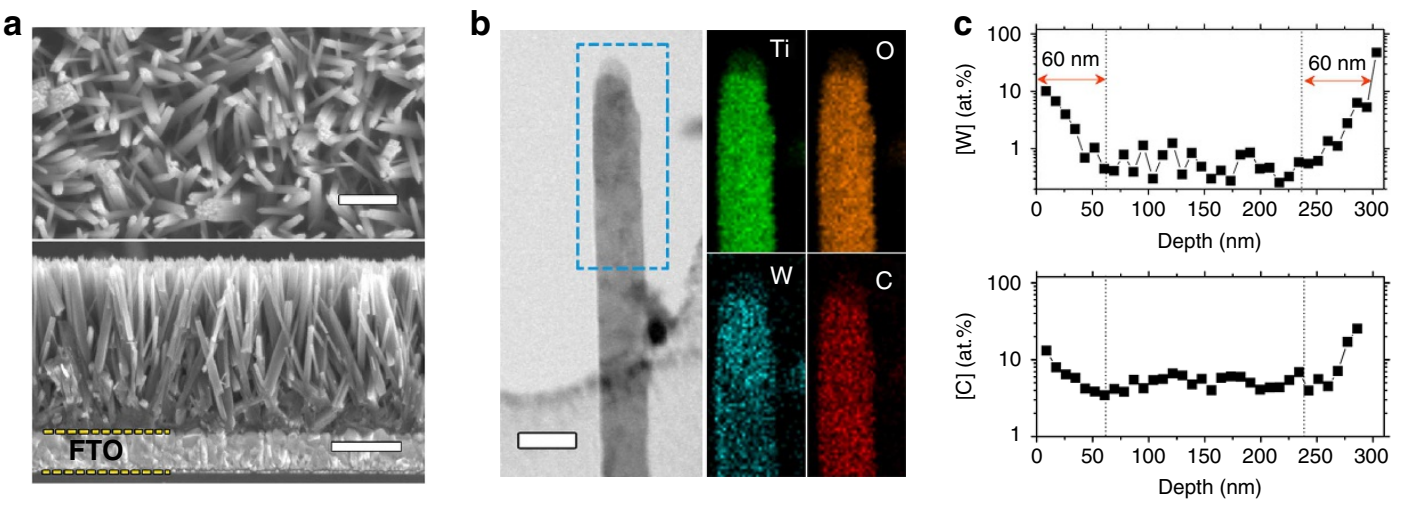

Figure 2 | Morphology and dopant-distribution characterization. (a) Top-view and cross-sectional scanning electron microscopy images. Scale bar, $500 \mathrm{~nm}$ (top view) and 1 um (cross-sectional). (b) TEM and energy-dispersive X-ray spectrometer mapping images. Scale bar, $100 \mathrm{~nm}$. (c) SIMS analysis of radial depth profiles for $\mathrm{W}$ and $\mathrm{C}$.
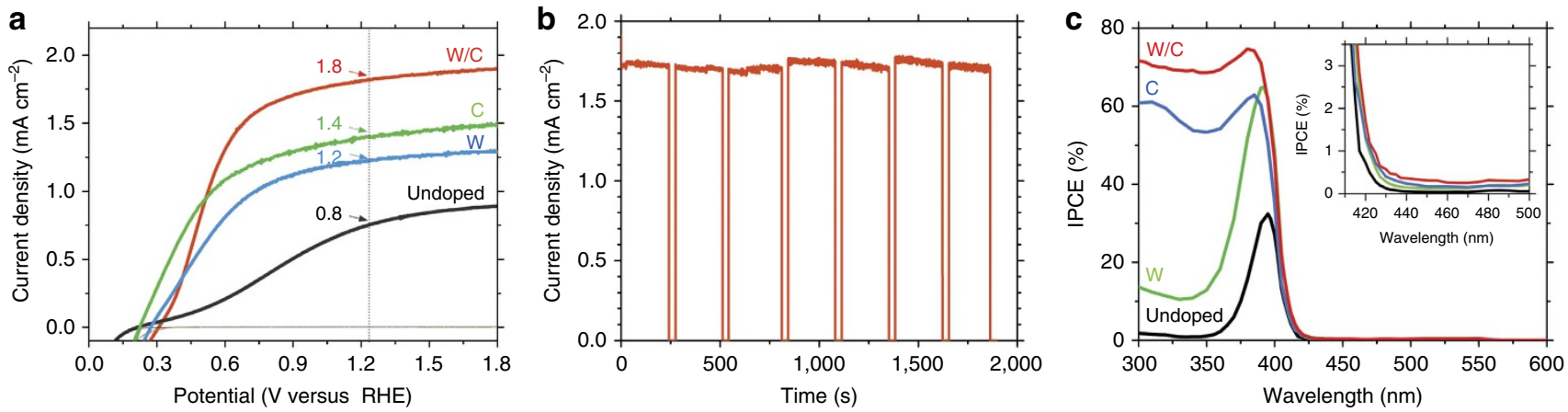

Figure 3 | Comparison of PEC performance. (a) Photocurrent-potential (J-V) curves of undoped, W-doped, C-doped and (W, C)-codoped TiO 2 NWs measured in a three-electrode setup $\left(\mathrm{TiO}_{2}\right.$ working, Pt-wire counter, SCE reference electrode, scan rate of $\left.50 \mathrm{mVs}^{-1}\right)$ and $1 \mathrm{M} \mathrm{KOH}$ electrolyte under simulated solar light illumination ( $\mathrm{AM} 1.5 \mathrm{G}, 100 \mathrm{~mW} \mathrm{~cm}^{-2}$ ). (b) The photocurrent density-time response shows good stability of TiO 2 :(W, C). (c) IPCE spectra measured at $1.23 \mathrm{~V}$ versus RHE. The inset shows a magnified view in the wavelength region of $400-500 \mathrm{~nm}$.

Morphology and dopants distribution. The morphology and dopant profiles of $\mathrm{TiO}_{2}:(\mathrm{W}, \mathrm{C}) \mathrm{NWs}$ are illustrated in Fig. 2. The cross-sectional and top views (Fig. 2a) show that the $\mathrm{TiO}_{2}:(\mathrm{W}, \mathrm{C})$ NWs have an average diameter of $100 \pm 10 \mathrm{~nm}$, length of $2.8 \pm 0.1 \mu \mathrm{m}$ and surface coverage density around $6.3 \times 10^{9} \mathrm{NWs}$ per $\mathrm{cm}^{2}$. The energy-dispersive X-ray spectrometer mapping, together with transmission electron microscope (TEM) image, (Fig. 2b), clearly shows that both $\mathrm{W}$ and $\mathrm{C}$ are doped over the entire $\mathrm{TiO}_{2} \mathrm{NW}$. The surface concentrations of $\mathrm{W}$ and $\mathrm{C}$ dopants are estimated to be $\sim 10.2 \pm 2.0$ at.\% and $13.1 \pm 3.0$ at.\%, respectively, via a quantitative analysis of the low loss and core-loss electron energy loss spectroscopy (EELS) spectra (Supplementary Fig. S4). The $\mathrm{W}$ and $\mathrm{C}$ dopant radial depth profiles within $\mathrm{TiO}_{2}$ NWs are analysed by the secondary ion mass spectrometry (SIMS) measurements for which we use larger $\mathrm{TiO}_{2}:(\mathrm{W}, \mathrm{C}) \mathrm{NWs}$ with an average diameter of $\sim 300 \mathrm{~nm}$ for higher secondary ion yield (Methods section and Supplementary Fig. S5). Figure 2c shows the radial depth profiles of $\mathrm{W}$ and $\mathrm{C}$ dopants, which are normalized by $\mathrm{Ti}$ and $\mathrm{O}$ counts, respectively. For both $\mathrm{W}$ and $\mathrm{C}$, their depth profiles show that the dopant concentration is high near the surface and then decreases along the radial direction towards the centre. The relatively symmetric shape of $\mathrm{W}$ and $\mathrm{C}$ dopant profiles along the diameter of the NW indicates homogeneous radial diffusion of $\mathrm{W}$ and $\mathrm{C}$. The SIMS profiles show that the radial diffusion depths for both $\mathrm{W}$ and $\mathrm{C}$ are about $60 \mathrm{~nm}$, so our $\mathrm{TiO}_{2}$ NWs ( $\sim 100 \mathrm{~nm}$ diameter) used for PEC tests are fully doped with $\mathrm{W}$ and $\mathrm{C}$ dopants, which is confirmed by EELS analysis (Supplementary Fig. S4).
PEC water-splitting performance. The PEC water-splitting performance of the codoped $\mathrm{TiO}_{2}:(\mathrm{W}, \mathrm{C}) \mathrm{NWs}$ is evaluated by measuring photocurrent density-potential $(J-V)$ curves using a standard three-electrode configuration under air mass (AM) $1.5 \mathrm{G}$ simulated solar light illumination $\left(100 \mathrm{~mW} \mathrm{~cm}^{-2}\right)$, and compared with undoped and monodoped ( $\mathrm{W}$ and $\mathrm{C}$ ) $\mathrm{TiO}_{2} \mathrm{NWs}$ (Fig. 3a). The monodoped $\mathrm{TiO}_{2} \mathrm{NWs}$ are prepared by using the identical doping conditions as the $\mathrm{TiO}_{2}:(\mathrm{W}, \mathrm{C})$ samples. First, the photocurrent density of the undoped $\mathrm{TiO}_{2} \mathrm{NWs}$ is $0.75 \mathrm{~mA} \mathrm{~cm}^{-2}$ at $1.23 \mathrm{~V}_{\mathrm{RHE}}$, which is comparable to previously reported values. ${ }^{34,35}$ Second, both monodoped $\mathrm{TiO}_{2}: \mathrm{W}$ and $\mathrm{TiO}_{2}: \mathrm{C}$ NWs, in comparison with the undoped $\mathrm{TiO}_{2} \mathrm{NWs}$, show much higher photocurrent density values, that is, 1.22 and $1.41 \mathrm{~mA} \mathrm{~cm}^{-2}$, respectively, at $1.23 \mathrm{~V}_{\mathrm{RHE}}$. More importantly, the codoped $\mathrm{TiO}_{2}:(\mathrm{W}, \mathrm{C}) \mathrm{NWs}$ have the highest photocurrent density of $1.81 \mathrm{~mA} \mathrm{~cm}^{-2}$ at $1.23 \mathrm{~V}_{\mathrm{RHE}}$, which is about 2.4 times higher than that of undoped $\mathrm{TiO}_{2}$ NWs, supporting the effectiveness of using donor-acceptor pairs to enhance PEC performance as suggested by previous theoretical calculations ${ }^{15,19}$. To the best of our knowledge, this is the first experimental demonstration for a donor-acceptor codoped $\mathrm{TiO}_{2}$ system that exhibits enhanced PEC water-splitting performance than monodoped $\mathrm{TiO}_{2}$. Finally, the stability of the codoped $\mathrm{TiO}_{2}:(\mathrm{W}, \mathrm{C}) \mathrm{NWs}$ is evaluated by measuring the photocurrent-time $(J-t)$ response (Fig. 3b). In the given 30-min experimental time interval, no obvious degradation of the photocurrent is observed. Significantly, even after over 6 months of storage in a strong base $(2 \mathrm{M} \mathrm{KOH})$ solution, the $J-V$ curve of the codoped $\mathrm{TiO}_{2}:(\mathrm{W}, \mathrm{C}) \mathrm{NWs}$ remains unchanged 

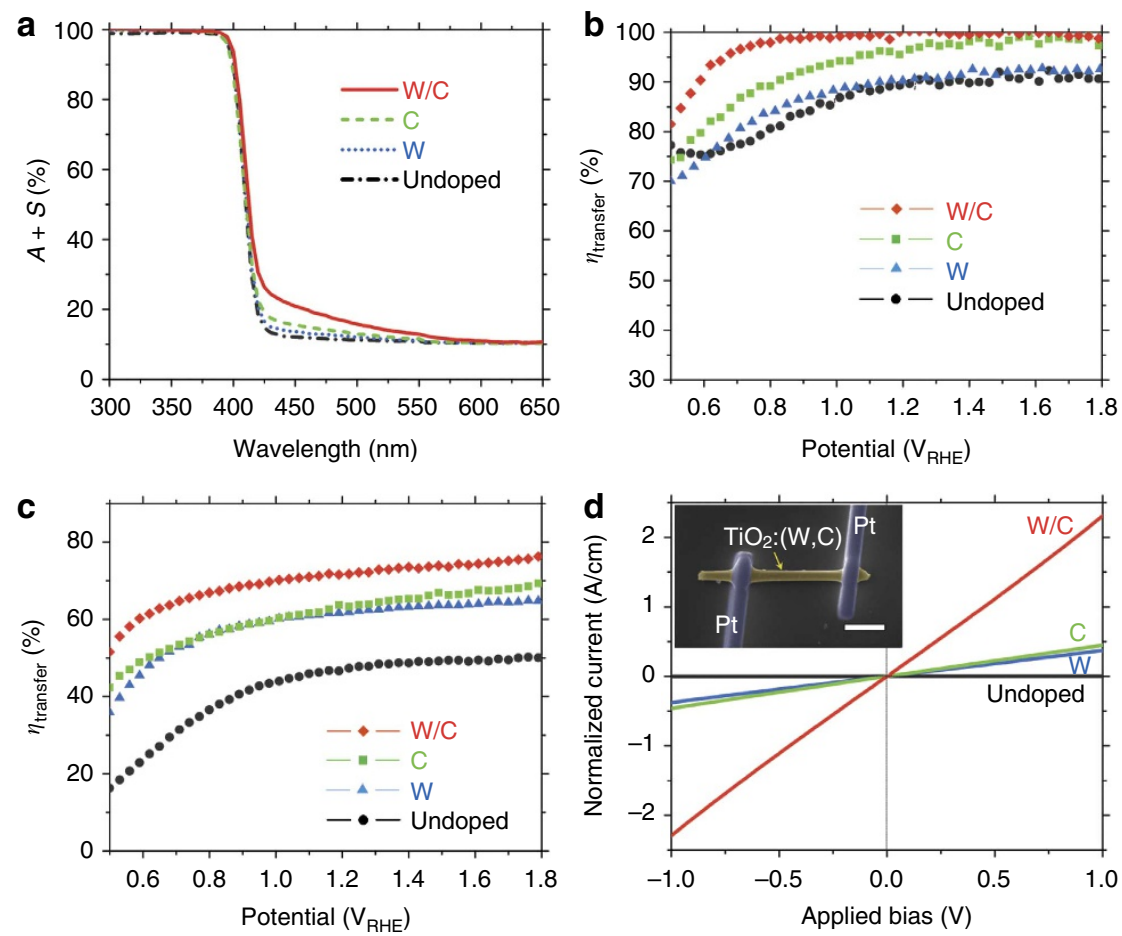

Figure 4 | Comparison of optical, charge transport and charge transfer properties. (a) Light absorption (plus scattering) of undoped (black), W-doped (blue), C-doped (green) and (W, C)-codoped $\mathrm{TiO}_{2} \mathrm{NW}$ (red) arrays grown on quartz. The integrated light absorption (plus scattering) values calculated by integrating over the wavelength, are $59.5 \%, 60.7 \%, 61.1 \%$ and $64.0 \%$ for undoped, W-doped, C-doped, and (W, C)-codoped $\mathrm{TiO}_{2} \mathrm{NWs}$, respectively. (b) Charge transport efficiencies. (c) Charge transfer efficiencies. (d) Current-voltage curves of single NW. The inset shows the scanning electron microscopy image of single $\mathrm{TiO}_{2}:(\mathrm{W}, \mathrm{C}) \mathrm{NW}$ with metal (Pt) contacts at both ends. Scale bar, $1 \mu \mathrm{m}$.

(Supplementary Fig. S6), indicating the excellent chemical stability of the $\mathrm{TiO}_{2}:(\mathrm{W}, \mathrm{C}) \mathrm{NWs}$.

The incident photon-to-current conversion efficiencies (IPCEs), equivalent to external quantum efficiency, of four samples (undoped, W-doped, C-doped and W/C-codoped $\mathrm{TiO}_{2}$ NWs) are measured at $1.23 \mathrm{~V}_{\mathrm{RHE}}$ where the photocurrent density values for all the samples are saturated. The IPCE values are plotted versus wavelength in Fig. $3 \mathrm{c}$ to compare the wavelengthdependent photocurrent response for the four $\mathrm{TiO}_{2} \mathrm{NWs}$. First, the codoped $\mathrm{TiO}_{2}:(\mathrm{W}, \mathrm{C})$ NWs have the highest IPCE values (IPCE $_{\max } \sim 80 \%$ at $380 \mathrm{~nm}$ ) throughout the whole wavelength region below the band gap $(\sim 420 \mathrm{~nm})$, and then the IPCE values are lowered in the order of C-doped (IPCE $\max \sim 66 \%$ at $385 \mathrm{~nm}$ ), W-doped (IPCE $\max \sim 64 \%$ at $390 \mathrm{~nm}$ ) and undoped $\mathrm{TiO}_{2}$ (IPCE $\max \sim 32 \%$ at $395 \mathrm{~nm}$ ). Second, the codoped $\mathrm{TiO}_{2}:(\mathrm{W}, \mathrm{C})$ NWs shows noticeable though very weak IPCE response at the visible-light region $(>420 \mathrm{~nm})$.

\section{Discussion}

IPCE of a PEC photoelectrode is determined by the efficiencies of three fundamental processes involved in PEC water-splitting reaction as illustrated in equation (1), that is, charge generation efficiency $\left(\eta_{e^{-}} / h^{+}\right)$, charge transport efficiency within the material $\left(\eta_{\text {transport }}\right)$ and charge transfer (collection) efficiency at the electrode/electrolyte interface $\left(\eta_{\text {transfer }}\right)^{8}$

$$
\operatorname{IPCE}(\lambda)=\eta_{e^{-} / h^{+}}(\lambda) \times \eta_{\text {transport }}(\lambda) \times \eta_{\text {transfer }}(\lambda)
$$

To identify the key factors responsible for the high IPCE for the $\mathrm{TiO}_{2}$ : $(\mathrm{W}, \mathrm{C}) \mathrm{NWs}$, the individual contributions of the above three factors are investigated separately. First, the light-absorption properties of the four $\mathrm{TiO}_{2}$ samples (undoped, W-doped,
C-doped and W/C-codoped) are measured (see Methods section) and compared over a wavelength range from 300 to $650 \mathrm{~nm}$ (Fig. 4a). Figure 4a shows the light-absorption spectra of the four $\mathrm{TiO}_{2} \mathrm{NW}$ arrays grown on quartz substrates. Although the $\mathrm{TiO}_{2}:(\mathrm{W}, \mathrm{C}) \mathrm{NWs}$ show slightly higher visible-light absorption tails in the wavelength region of $420-580 \mathrm{~nm}$, its integrated light absorption $(\sim 64 \%)$ over $300-580 \mathrm{~nm}$ is comparable to the other three samples, indicating that codoping within our doping conditions has little impact on the light absorption or charge generation efficiency $\left(\eta_{e^{-} / h^{+}}\right)$.

Furthermore, the charge transport efficiency ( $\left.\eta_{\text {transport }}\right)$ and charge transfer efficiency ( $\left.\eta_{\text {transfer }}\right)$ are decoupled and quantified by using $\mathrm{H}_{2} \mathrm{O}_{2}$ as a hole scavenger approach (see Methods section $)^{36}$. The estimated charge transfer and transport efficiencies of the four $\mathrm{TiO}_{2}$ samples are compared in Fig. 4b,c. For the estimated charge transfer efficiency (Fig. $4 \mathrm{~b}$ ), because the rutile $\mathrm{TiO}_{2}$, especially the (110) terminated surface, has high catalytic activity towards $\mathrm{OER}, 37,38$, all of the four $\mathrm{TiO}_{2}$ samples show relatively high charge transfer efficiencies exceeding 70\% throughout the whole potential range. Furthermore, the codoped $\mathrm{TiO}_{2}:(\mathrm{W}, \mathrm{C}) \mathrm{NWs}$ sample has the highest charge transfer efficiency $(99 \%)$ at $1.23 \mathrm{~V}_{\mathrm{RHE}}$, in comparison with the undoped (89\%), W-doped (91\%) and C-doped (96\%) samples. The observed charge transfer efficiency difference suggests that the presence of donor-acceptor pair effectively reduces the surface recombination of charge carriers, especially at the low potential region $\left(<1.0 \mathrm{~V}_{\mathrm{RHE}}\right)$. The OER activity is also improved on monodoped rutile $\mathrm{TiO}_{2}$ (110) surface that is consistent with the recent theoretical predication based on density-functional theory calculations. ${ }^{39}$ Previous experimental studies also suggest that the monodoping can induce high surface acidity and increase of reactant adsorption, ${ }^{40,41}$ enhancing the 
a

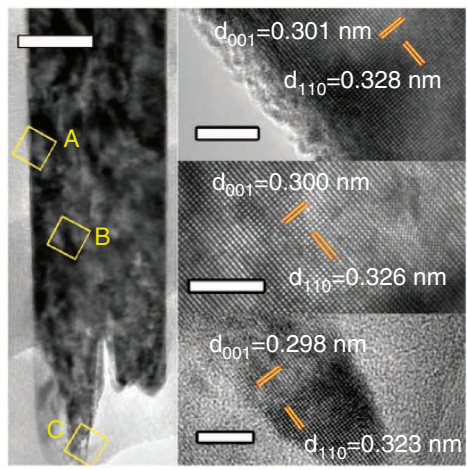

b

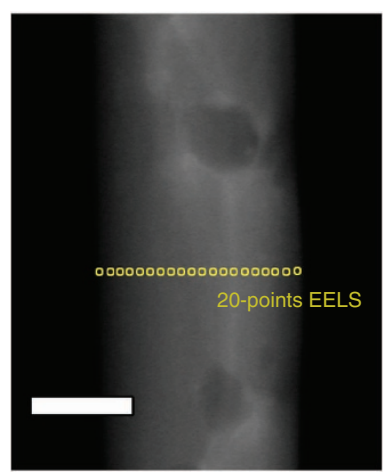

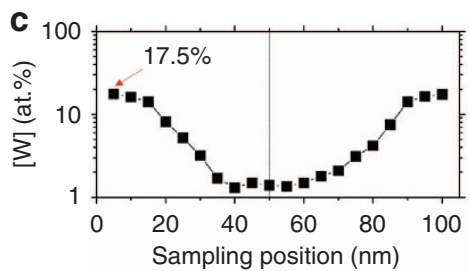

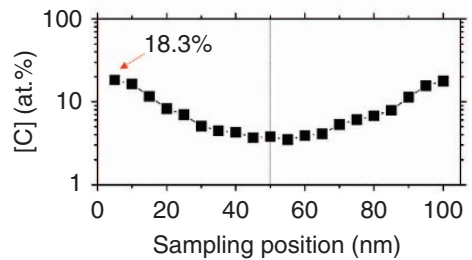

d

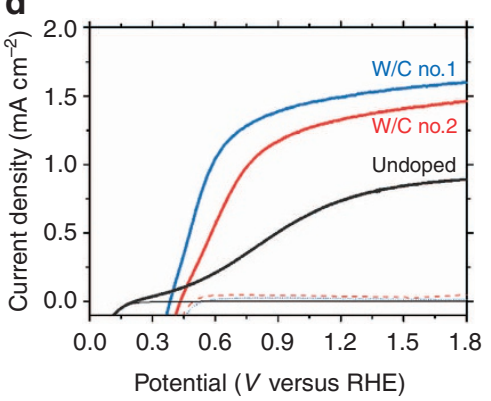

e
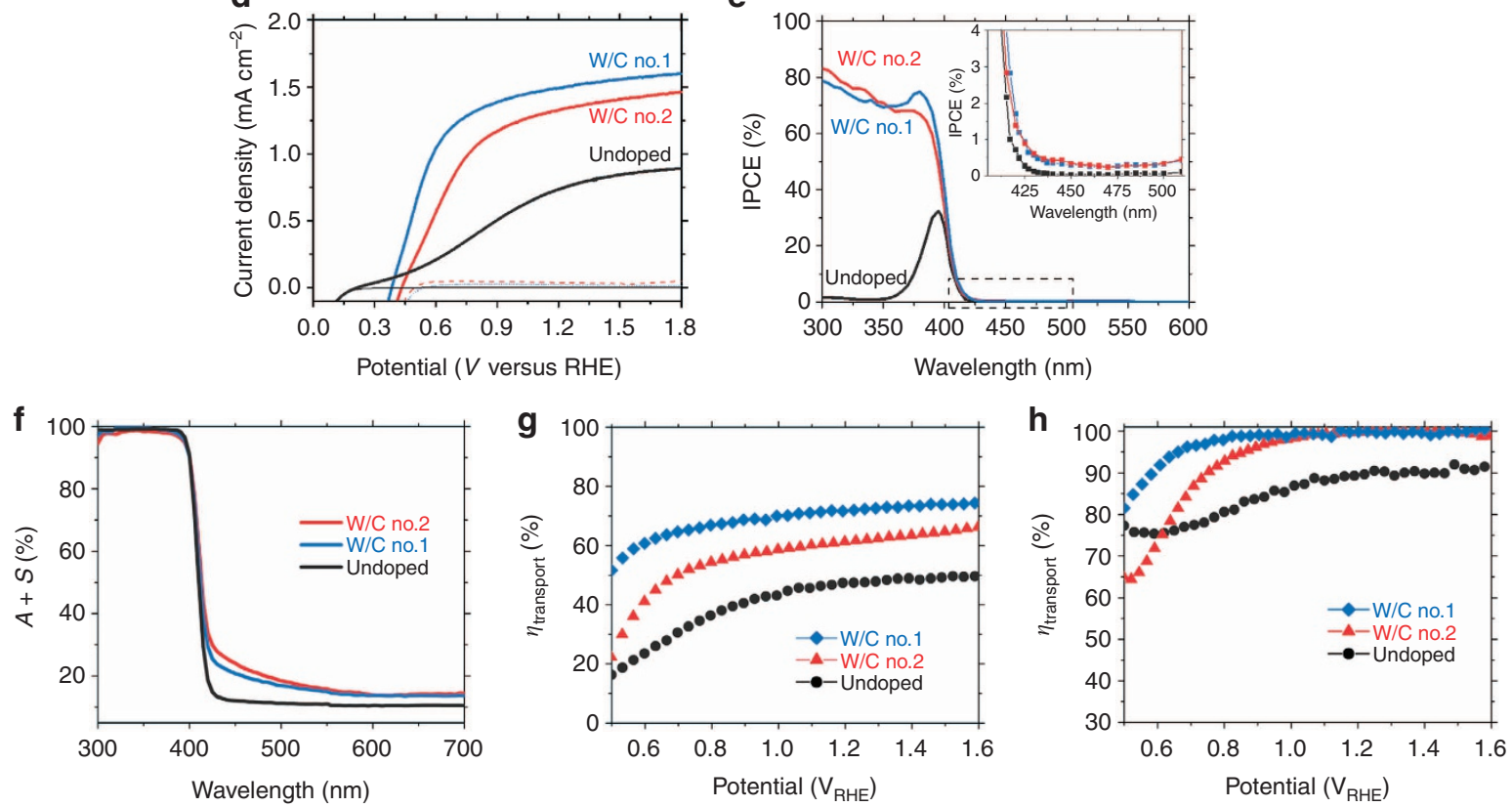

Figure 5 | Characterization and PEC water-splitting performance of $\mathrm{TiO}_{\mathbf{2}} \mathbf{N W s}$ with high $\mathbf{W}$ - and $\mathbf{C}$-doping concentrations. (a) TEM and high-resolution TEM images of W/C no. 2 (W: 17.5 at.\%, C: 18.3 at.\% at the NW surface). Scale bar, 50 nm (TEM) and 5 nm (high-resolution TEM). (b) STEM image. Scale bar, $50 \mathrm{~nm}$. (c) Concentration profiles of W and C dopants along the NW diameter in W/C no. 2. Comparison of W/C no. 1 (blue) and W/C no. 2 (red) with (d), three electrodes J-V curves (W/C no. 1, W: 10.2 at.\%, C: 13.1 at.\% at the NW surface), (e) IPCE, (f) light absorption (quartz substrate), (g) charge transfer efficiency and (h) charge transport efficiency. The data of undoped $\mathrm{TiO}_{2} \mathrm{NWs}$ (black) are added for reference.

charge transfer process. Finally, though the codoped $\mathrm{TiO}_{2}$ : $(\mathrm{W}, \mathrm{C})$ NWs improves the charge transfer efficiency approximately by $10 \%$, the improvement is not large enough to explain its 2.4 times higher saturation photocurrent density value.

The third and last factor affecting the IPCE value is the charge transport efficiency, for which both electron and hole transport is important and mostly affected by the bulk recombination process. As shown in Fig. 4c, the codoped $\mathrm{TiO}_{2}:(\mathrm{W}, \mathrm{C}) \mathrm{NWs}$ sample has the highest estimated charge transport efficiency (50-80\%), on average over two times higher than that of the undoped $\mathrm{TiO}_{2} \mathrm{NWs}$. The transport efficiency for monodoped $\mathrm{TiO}_{2}: \mathrm{W}$ and $\mathrm{TiO}_{2}: \mathrm{C}$ samples are in between those of the codoped and undoped samples, very similar to the PEC performance shown in Fig. 3a. The electron-transport property is further compared by measuring the conductivity of individual $\mathrm{TiO}_{2}$ NWs (see Methods section). Figure 4d shows linear current-voltage $(I-V)$ curves for four individual $\mathrm{TiO}_{2} \mathrm{NWs}$, indicating good ohmic contact. The calculated electrical conductivity values of the undoped, W-doped, C-doped and W/C- codoped samples are $\sim 0.0001,0.37,0.46$ and $2.26 \mathrm{~S} \mathrm{~cm}^{-1}$, respectively. The $\mathrm{W}$-doped, $\mathrm{C}$-doped and $\mathrm{W} / \mathrm{C}$-codoped samples have over three orders of magnitude higher conductivity than the undoped sample, suggesting that doping $\mathrm{TiO}_{2}$ with $\mathrm{W}$ and/or C significantly improves the electron-transport property. It should be noted that codoping gives higher conductivity improvement than the monodoping cases, indicating the defect passivation effect by codoping of $\mathrm{W}$ (donor) and $\mathrm{C}$ (acceptor). On the other hand, the improvement of charge transport efficiency is much lower than the increase of the electrical conductivity, suggesting that the bulk recombination, likely hole transport, is still the bottleneck for the overall charge transport process. Considering all the three factors, that is, light absorption, charge transport and transfer properties, the most pronounced effect of codoping for $\mathrm{TiO}_{2}$ is to improve the charge transport property, that is, increasing electrical conductivity, and a minor effect is to improve the surface OER activity.

We further synthesized W/C-codoped $\mathrm{TiO}_{2} \mathrm{NWs}$ with higher doping concentration (W/C no. 2) than the optimally codoped 
$\mathrm{TiO}_{2}$ : (W, C) NWs (W/C no. 1, the sample discussed above) by using higher molar concentration of $\mathrm{W}$-precursor solution $(0.1 \mathrm{M})$ and longer duration of $\mathrm{CO}$ gas annealing $\left(550^{\circ} \mathrm{C}\right.$ for $1 \mathrm{~h})$. As shown in Fig. $5 \mathrm{a}-\mathrm{c}$, the W/C no. 2 has much higher W (17.5 at.\%) and C (18.3 at.\%) surface doping concentrations than the W/C no. 1 (optimal sample for PEC, W: 10.2 at.\%, C: 13.1 at.\% at the NW surface). Even though the W/C no. 2 has such high $\mathrm{W}$ - and C-doping concentrations, there is no nanoparticle formation at the $\mathrm{TiO}_{2} \mathrm{NW}$ surface and the highresolution TEM images at the region of $\mathrm{A}, \mathrm{B}$ and $\mathrm{C}$ (Fig. 5a) also confirms that the W/C no. 2 remains to be highly crystalline without dopant segregation. In comparison with the W/C no. 1, the W/C no. 2 exhibits inferior PEC water-splitting performance with lower saturation photocurrent density and lower IPCE values (especially near the band-edge wavelength region, 360-400 nm) (Fig. 5d,e). Finally, both W/C no. 1 and W/C no. 2 exhibit $<1 \%$ IPCE values in the visible-light wavelength region $(420-550 \mathrm{~nm})$. To identify the reasons for the lower performance of $\mathrm{W} / \mathrm{C}$ no. 2, we again determine the individual efficiency of the three processes that governs the PEC water-splitting performance, that is, light absorption (charge generation), charge transport and charge transfer efficiency, as shown in Fig. 5f-h. First, the visiblelight absorption ( $>420 \mathrm{~nm}$ ) of the W/C no. 2 with higher $\mathrm{W}$ - and $\mathrm{C}$-doping concentrations is obviously higher than that of the W/C no. 1 sample (Fig. $5 f$ ). Nevertheless, the IPCE in this visible-light region is nearly zero. Second, the charge transfer efficiency of W/ $\mathrm{C}$ no. 2 is lower than that of W/C no. 1 , especially at lower applied potential region (Fig. $5 \mathrm{~g}$ ). It is likely due to decreased OER activity by higher $\mathrm{W}$ and $\mathrm{C}$ concentration at the $\mathrm{TiO}_{2}$ surface $^{10}$. Third, the charge transport efficiency of W/C no. 2 is consistently lower than that of W/C no. 1 over the entire applied potential range (Fig. 5h). This large decrease of charge transport efficiency in W/C no. 2 likely comes from the decreased conductivity due to the enhanced dopant scattering effect at much higher doping concentration. ${ }^{42}$ As a result, though the $\mathrm{TiO}_{2}$ NWs with higher doping concentration of $\mathrm{W}$ and $\mathrm{C}$ dopants exhibit increased visible-light absorption, their IPCE in the visible light range is still very weak (about $0.5 \%$ ). In addition, the $\mathrm{TiO}_{2}$ NWs with higher doping concentration of $\mathrm{W}$ and $\mathrm{C}$ dopants exhibit lower charge transport and charge transfer efficiencies, and hence lower PEC performance than those of the optimal sample.

In summary, we report the first experimental demonstration that codoping $\mathrm{TiO}_{2} \mathrm{NW}$ s with $\mathrm{W}$ and $\mathrm{C}$ indeed greatly enhances the PEC water-splitting performance compared to the monodoped and undoped $\mathrm{TiO}_{2}$ NWs. Our novel ex-situ sol-flame doping method effectively dopes $\mathrm{TiO}_{2}$ NWs with W without changing the morphology and crystallinity of $\mathrm{TiO}_{2} \mathrm{NWs}$ and without damaging the delicate FTO substrate. The codoped $\mathrm{TiO}_{2}$ :(W, C) NWs exhibit improved saturation photocurrent density than monodoped $\mathrm{TiO}_{2}: \mathrm{W}$ and $\mathrm{TiO}_{2}: \mathrm{C}$ and 2.4 times higher saturation photocurrent density than the undoped $\mathrm{TiO}_{2}$ NWs, and the enhancement is attributed to mainly charge transport efficiency improvement and minor charge transfer efficiency improvement. We believe that the effectiveness of our doping method and codoping strategies, together with theoretical guidance, will enable further improvement of the PEC watersplitting performance of many other metal-oxide photoanodes.

\section{Methods}

Synthesis of rutile $\mathrm{TiO}_{2} \mathbf{N W s}$ array. The pristine $\mathrm{TiO}_{2} \mathrm{NW}$ arrays were synthesized on $\mathrm{TiO}_{2}$ nanoparticle-coated FTO substrates using the hydrothermal method, and the details were reported in our previous work ${ }^{34}$. Briefly, for a typical synthesis, $0.6 \mathrm{ml}$ of titanium (IV) butoxide (Aldrich Chemicals, 97\%) was added into $50 \mathrm{ml}$ of an aqueous $\mathrm{HCl}$ solution $(25 \mathrm{ml}$ of deionized (DI) water $+25 \mathrm{ml}$ of concentrated $\mathrm{HCl}(38 \%)$ ) under magnetic stirring. For the growth of larger diameter $\mathrm{TiO}_{2}$ NWs that were used for the SIMS analysis, larger amount of Ti-butoxide $(1 \mathrm{ml})$ was added and the growth substrate was quartz. After stirring for another $5 \mathrm{~min}$, the solution was poured into a Teflon-lined stainless steel autoclave ( $100 \mathrm{ml}$ capacity), and pieces of the $\mathrm{TiO}_{2}$ nanoparticle-coated FTO substrates, which have been cleaned for $10 \mathrm{~min}$ using an ultrasonicator in a mixed solution of DI water, acetone and isopropanol (IPA), were immersed in the solution. The autoclave was sealed and heated to $170^{\circ} \mathrm{C}$ in an oven, and held at $170^{\circ} \mathrm{C}$ for $7 \mathrm{~h}$. The autoclave was then removed from the oven and allowed to cool to room temperature naturally on the bench top. The obtained products were washed with DI water and finally annealed at $450{ }^{\circ} \mathrm{C}$ for $1 \mathrm{~h}$ in air.

Preparation of $\mathbf{W}$-dopant precursor solution. The W-dopant precursor solutions with metal salt concentrations of $0.01-0.2 \mathrm{M}$ were prepared by using tungstic acid $\left(\mathrm{H}_{2} \mathrm{WO}_{4}, 99 \%\right.$; Sigma-Aldrich Chemicals), hydrogen peroxide $\left(\mathrm{H}_{2} \mathrm{O}_{2}, 30 \%\right.$; SigmaAldrich Chemicals) and 2-methoxyethanol $\left(\mathrm{C}_{3} \mathrm{H}_{8} \mathrm{O}_{2},>99 \%\right.$; Acros Organics) with a three-step sol-gel method: (1) dissolving the desired amount of $\mathrm{H}_{2} \mathrm{WO}_{4}$ into 6-10 $\mathrm{ml}$ of $\mathrm{H}_{2} \mathrm{O}_{2}$, (2) removing excess $\mathrm{H}_{2} \mathrm{O}_{2}$ and water by evaporation of the solution on a hot plate $\left(130^{\circ} \mathrm{C}\right)$ until the amount of the remained solution was about $1 \mathrm{ml}$ and (3) mixing the $1 \mathrm{ml}$ solution with 2-methoxyethanol by sonication $(5 \mathrm{~min})$ and stirring $(1 \mathrm{~h})$. After aging for 6-12 h, the prepared precursor solution was used for dip-coating the as-synthesized $\mathrm{TiO}_{2}$ NWs.

Doping $\mathrm{TiO}_{2} \mathbf{N W s}$ with $\mathbf{W}$ and/or C. (i) To dope W into $\mathrm{TiO}_{2} \mathrm{NWs}$, the prepared $\mathrm{W}$-precursor solution was coated over the entire surface of $\mathrm{TiO}_{2} \mathrm{NWs}$ by the dip-coating method ${ }^{43,44}$. After drying by air $\left(\right.$ or $\mathrm{N}_{2}$ ) blowing and subsequent air-annealing at $80^{\circ} \mathrm{C}$ for $10 \mathrm{~min}$, the $\mathrm{W}$-precursor-coated $\mathrm{TiO}_{2} \mathrm{NWs}$ were annealed in a premixed flame of $1,100^{\circ} \mathrm{C}$ for $2 \mathrm{~min}$ with a stoichiometric fuel-tooxidizer equivalence ratio $(\Phi)$ of 1.0 (the flow rates of $\mathrm{CH}_{4}$ and air were 2.0 and 25.5 SLPM (standard liters per minute), respectively). ${ }^{43,44}$ The stoichiometric condition and usage of $\mathrm{CH}_{4}$ minimizes the possibility of forming oxygen vacancy and carbon deposition on the $\mathrm{TiO}_{2}$ NWs. (ii) For the C doping, the as-synthesized or W-doped $\mathrm{TiO}_{2} \mathrm{NWs}$

were annealed in a tube furnace $\left(550^{\circ} \mathrm{C}\right.$ for $\left.30 \mathrm{~min}\right)$ with $30 \mathrm{sccm} \mathrm{CO}$ gas flow. For codoping of $\mathrm{W}$ and $\mathrm{C}$, sequential doping process of (i) and (ii) was used. The dependence of PEC performance on the doping conditions is discussed in detail in Supplementary Fig. S2.

Material characterizations and dopant depth profiles. The morphologies of undoped and doped $\mathrm{TiO}_{2}$ NWs were investigated using a scanning electron microscopy (FEI XL30; Sirion). The dopant distribution and surface concentration were investigated using a TEM (F20 FEI Tecnai, $200 \mathrm{kV}$ ) equipped with an energydispersive X-ray spectrometer and an EELS (Supplementary Fig. S4). SIMS measurements were conducted to analyse the radial depth profiles of $\mathrm{W}$ and $\mathrm{C}$ in $\mathrm{TiO}_{2}$ :(W, C) NWs. To increase the secondary ion yield for SIMS measurement, larger diameter $\mathrm{TiO}_{2} \mathrm{NWs}(\sim 300 \mathrm{~nm})$ were grown on quartz substrates using larger amount of Ti-butoxide $(1 \mathrm{ml})$ addition. After doping with $\mathrm{W}$ and $\mathrm{C}$, the $\mathrm{TiO}_{2}$ : $(\mathrm{W}, \mathrm{C}) \mathrm{NW}$ sere sonicated in IPA. The NW suspension was then drop-cast onto a piece of $\mathrm{Si}(100)$ wafer to disperse $\mathrm{TiO}_{2} \mathrm{NWs}$ on the Si substrate. To remove the solvent residue, the NW-deposited Si substrate was washed with DI water and dried in a vacuum. The SIMS measurements were carried out using a Cameca NanoSIMS-50. A Cs ${ }^{+}$primary ion beam, accelerated at $16 \mathrm{keV}$ with a $3.6 \mathrm{pA}$ beam current, was used to sputter the surface of the NWs. The ${ }^{12} \mathrm{C},{ }^{18} \mathrm{O}$, ${ }^{28} \mathrm{Si},{ }^{48} \mathrm{Ti},{ }^{48} \mathrm{Ti}{ }^{16} \mathrm{O}$ and ${ }^{184} \mathrm{~W}^{16} \mathrm{O}$ secondary ions and ionic fragments were collected and analysed in a mass spectrometer. The rastered area was $1 \times 1 \mu \mathrm{m}^{2}$ and the gated/analysis area was the centre $0.25 \mu \mathrm{m}^{2}$ area to ensure that the collected counts only come from the NWs (Supplementary Fig. S5). The sputtering rate was estimated by using the $\mathrm{TiO}_{2} \mathrm{NW}$ diameter and the depth profile of ${ }^{28} \mathrm{Si}$.

Optical measurements. As FTO and the underlying glass can contribute to background absorption in the longer wavelength regime, $\mathrm{TiO}_{2} \mathrm{NWs}$ for the optical measurements were grown on the quartz substrate instead. The wavelengthdependent optical absorption properties were obtained with an integrating sphere using a xenon lamp coupled to a monochromator (Model QEX7; PV Measurements, Inc.). The absorption plus scattering was calculated from these measurements with the formula $A+S=1-\mathrm{T}-\mathrm{R}$, where $A$ is the absorption, $S$ is the scattered light that was not accounted for in the measurement, $T$ is the total transmittance and $R$ is the total reflectance.

Electronic transport properties measurement. To measure electronic transport properties of single $\mathrm{TiO}_{2}$ NWs, the NWs were sonicated in IPA and then drop-cast onto a $\mathrm{SiO}_{2} / \mathrm{Si}$ substrate ${ }^{45}$. Platinum $(\mathrm{Pt})$ metal contacts were deposited on the both ends of each $\mathrm{TiO}_{2}$ NWs by using the focused ion beam (FEI Strata DB235) ${ }^{46}$. Current-voltage $(I-V)$ measurements were conducted at room temperature using a semiconductor analyser (Model 4200-SCS; Keithley) with tungsten probes. 
PEC measurements. The PEC performance of undoped and doped $\mathrm{TiO}_{2} \mathrm{NWs}$ was measured using a potentiostat (Model SP-200; BioLogic) in a three-electrode configuration (a saturated calomel reference electrode (SCE) and a Pt-wire counter electrode) under illumination of simulated solar light (AM $1.5 \mathrm{G}, 100 \mathrm{~mW} \mathrm{~cm}^{-2}$ ) using solar simulator (Model 94306A, Class AAA; Oriel). Before the measurement, the solar simulator intensity was calibrated with a reference silicon solar cell and a readout metre for solar simulator irradiance (Mode 91150V; Newport). The illuminated area of the working $\mathrm{TiO}_{2}$ electrode was $0.63 \mathrm{~cm}^{2}$ defined by a mask. A volume of $1 \mathrm{M} \mathrm{KOH}$ or $1 \mathrm{M} \mathrm{KOH}$ with $0.5 \mathrm{M} \mathrm{H}_{2} \mathrm{O}_{2}$ solution was used as the electrolyte. During the PEC measurement, the electrolyte was deaerated by Ar purging to remove the dissolved oxygen. In a typical $J-V$ measurement, the voltage was swept linearly from -1.0 to $2.0 \mathrm{~V}_{\mathrm{SCE}}$ at a scan rate of $50 \mathrm{mV} \mathrm{s}^{-1}$. The IPCE was measured at $1.23 \mathrm{~V}_{\mathrm{RHE}}\left(=\sim 0.2 \mathrm{~V}_{\mathrm{SCE}}\right)$ using a specially designed IPCE system for solar cell (QEX7; PV measurements), with three-electrode configuration. A 75-W Xe lamp equipped with a monochromator (CM-110, 1/8; SP Spectra Product) was used to generate a monochromatic beam. The incident light intensity was calibrated by a standard silicon photodiode. The charge transport and transfer efficiencies were estimated as functions of applied potential by using $\mathrm{H}_{2} \mathrm{O}_{2}$ as a hole scavenger under AM $1.5 \mathrm{G}$ simulated solar light illumination ${ }^{36}$. The key assumption for this approach is that the oxidation kinetics of $\mathrm{H}_{2} \mathrm{O}_{2}$ is very fast and its charge transfer efficiency is $100 \%$, so the ratio of photocurrent density measured in $\mathrm{H}_{2} \mathrm{O}$ and $\mathrm{H}_{2} \mathrm{O}_{2}$ gives the charge transfer efficiency $\left(\eta_{\text {transfer }}\right)$ for $\mathrm{H}_{2} \mathrm{O}$ (equation 2$)$. The charge transport efficiency $\left(\eta_{\text {transport }}\right)$ was further calculated by dividing photocurrent density in $\mathrm{H}_{2} \mathrm{O}_{2}$ by the total light-absorption efficiency $\left(\eta_{e^{-}} / h^{+}\right)$, which is obtained from integration of light absorption (Fig. $4 \mathrm{a}$ ) with respect to the AM $1.5 \mathrm{G}$ solar light spectrum (equation 3).

$$
\begin{gathered}
\eta_{\text {transfer }}=\frac{J_{\mathrm{ph}, \mathrm{H}_{2} \mathrm{O}}}{J_{\mathrm{ph}, \mathrm{H}_{2} \mathrm{O}_{2}}} \\
\eta_{\text {transport }}=\frac{J_{\mathrm{ph}, \mathrm{H}_{2} \mathrm{O}_{2}}}{\eta_{e^{-} / h^{+}}}
\end{gathered}
$$

\section{References}

1. Linsebigler, A. L., Lu, G. \& Yates, J. T. Photocatalysis on $\mathrm{TiO}_{2}$ surfaces: principles, mechanisms, and selected results. Chem. Rev. 95, 735-758 (1995).

2. Bak, T., Nowotny, J., Rekas, M. \& Sorrell, C. C. Photo-electrochemical hydrogen generation from water using solar energy. Materials-related aspects. Int. J. Hydrogen Energy 27, 991-1022 (2002).

3. Nowotny, J., Sorrell, C. C., Bak, T. \& Sheppard, L. R. Solar-hydrogen: Unresolved problems in solid-state science. Solar Energy 78, 593-602 (2005).

4. Ni, M., Leung, M. K. H., Leung, D. Y. C. \& Sumathy, K. A review and recent developments in photocatalytic water-splitting using for hydrogen production. Renewable and Sustainable Energy Rev. 11, 401-425 (2007).

5. Fujishima, A. \& Honda, K. Electrochemical photolysis of water at a semiconductor electrode. Nature 238, 37-38 (1972).

6. Hoffmann, M. R., Martin, S. T., Choi, W. \& Bahnemann, D. W. Environmental applications of semiconductor photocatalysis. Chem. Rev. 95, 69-96 (1995).

7. Chen, X. \& Mao, S. S. Titanium dioxide nanomaterials: synthesis, properties, modifications, and applications. Chem. Rev. 107, 2891-2959 (2007).

8. Chen, Z. et al. Accelerating materials development for photoelectrochemical hydrogen production: standards for methods, definitions, and reporting protocols. J. Mater. Res. 25, 3-16 (2010).

9. Murphy, A. B. et al. Efficiency of solar water splitting using semiconductor electrodes. Int. J. Hydrogen Energy 31, 1999-2017 (2006).

10. Choi, W., Termin, A. \& Hoffmann, M. R. The role of metal ion dopants in quantum-sized $\mathrm{TiO}_{2}$ : correlation between photoreactivity and charge carrier recombination dynamics. J. Phys. Chem. 98, 13669-13679 (1994).

11. Asahi, R., Morikawa, T., Ohwaki, T., Aoki, K. \& Taga, Y. Visible-light photocatalysis in nitrogen-doped titanium oxides. Science 293, 269-271 (2001).

12. Park, J. H., Kim, S. \& Bard, A. J. Novel carbon-doped $\mathrm{TiO}_{2}$ nanotube arrays with high aspect ratios for efficient solar water splitting. Nano Lett. 6, 24-28 (2005).

13. Khan, S. U. M., Al-Shahry, M. \& Ingler, W. B. Efficient photochemical water splitting by a chemically modified $n-\mathrm{TiO}_{2}$. Science $297,2243-2245$ (2002).

14. Hashimoto, K., Irie, H. \& Fujishima, A. $\mathrm{TiO}_{2}$ photocatalysis: A historical overview and future prospects. Japn. J. Appl. Phys. Part 1 Regular Papers Brief Commun. Rev. Papers 44, 8269-8285 (2005)

15. Yin, W.-J. et al. Band structure engineering of semiconductors for enhanced photoelectrochemical water splitting: the case of $\mathrm{TiO}_{2}$. Phys. Rev. B 82, 045106 (2010).

16. Gai, Y., Li, J., Li, S.-S., Xia, J.-B. \& Wei, S.-H. Design of narrow-gap $\mathrm{TiO}_{2}$ : a passivated codoping approach for enhanced photoelectrochemical activity. Phys. Rev. Lett. 102, 036402 (2009).

17. Wang, P. et al. Optimizing photoelectrochemical properties of $\mathrm{TiO}_{2}$ by chemical codoping. Phy. Rev. B 82, 193103 (2010).
18. Ma, X. et al. Effect of compensated codoping on the photoelectrochemical properties of anatase $\mathrm{TiO}_{2}$ photocatalyst. J. Phys. Chem. C 115, 16963-16969 (2011).

19. Wang, D., Zou, Y., Wen, S. \& Fan, D. A passivated codoping approach to tailor the band edges of $\mathrm{TiO}_{2}$ for efficient photocatalytic degradation of organic pollutants. Appl. Phys. Lett. 95, 012106-012106-3 (2009)

20. Long, R. \& English, N. J. First-principles calculation of nitrogen-tungsten codoping effects on the band structure of anatase-titania. Appl. Phys. Lett. 94, 132102-132103 (2009).

21. Niu, M., Xu, W., Shao, X. \& Cheng, D. Enhanced photoelectrochemical performance of rutile $\mathrm{TiO}_{2}$ by Sb-N donor-acceptor coincorporation from first principles calculations. Appl. Phys. Lett. 99, 203111-203113 (2011).

22. Zhu, W. et al. Band gap narrowing of titanium oxide semiconductors by noncompensated anion-cation codoping for enhanced visible-light photoactivity. Phys. Rev. Lett. 103, 226401 (2009).

23. Breault, T. M. \& Bartlett, B. M. Lowering the band gap of anatase-structured $\mathrm{TiO}_{2}$ by coalloying with $\mathrm{Nb}$ and $\mathrm{N}$ : electronic structure and photocatalytic degradation of methylene blue dye. J. Phys. Chem. C 116, 5986-5994 (2012).

24. Wang, E., He, T., Zhao, L., Chen, Y. \& Cao, Y. Improved visible light photocatalytic activity of titania doped with tin and nitrogen. J. Mater. Chem. 21, 144-150 (2011)

25. Liu, H. et al. $(\mathrm{Mo}+\mathrm{N})$ codoped $\mathrm{TiO}_{2}$ for enhanced visible-light photoactivity. Appl. Surf. Sci. 257, 9355-9361 (2011).

26. Kubacka, A., Bachiller-Baeza, B.n., Coloó;n, G. \& Fernaóndez-Garció, M. W,Ncodoped tio $_{2}$-anatase: a sunlight-operated catalyst for efficient and selective aromatic hydrocarbons photo-oxidation. J. Phys. Chem. C 113, 8553-8555 (2009).

27. Obata, K., Irie, H. \& Hashimoto, K. Enhanced photocatalytic activities of Ta, $\mathrm{N}$ co-doped $\mathrm{TiO}_{2}$ thin films under visible light. Chem. Phys. 339, 124-132 (2007).

28. Joseph, M., Tabata, H., Saeki, H., Ueda, K. \& Kawai, T. Fabrication of the low-resistive p-type $\mathrm{ZnO}$ by codoping method. Physica B 302, 140-148 (2001).

29. Ahn, K.-S. et al. Enhanced photoelectrochemical responses of $\mathrm{ZnO}$ films through Ga and N codoping. Appl. Phys. Lett. 91, 231909-231909-3 (2007).

30. Ban, C. et al. A novel codoping approach for enhancing the performance of $\mathrm{LiFePO}_{4}$ cathodes. Adv. Energy Mater. 2, 1028-1032 (2012).

31. Neville, E. M. et al. Carbon-doped $\mathrm{TiO}_{2}$ and carbon, tungsten-codoped tio through sol-gel processes in the presence of melamine borate: reflections through photocatalysis. J. Phys. Chem. C 116, 16511-16521 (2012).

32. Zhou, X., Peng, F., Wang, H. \& Yu, H. Boron and nitrogen-codoped $\mathrm{TiO}_{2}$ nanorods: synthesis, characterization, and photoelectrochemical properties. J. Solid State Chem. 184, 3002-3007 (2011).

33. Thind, S. S., Wu, G. \& Chen, A. Synthesis of mesoporous nitrogen-tungsten co-doped $\mathrm{TiO}_{2}$ photocatalysts with high visible light activity. Appl. Catalysis B: Environ. 111-112, 38-45 (2012).

34. Cho, I. S. et al. Branched $\mathrm{TiO}_{2}$ nanorods for photoelectrochemical hydrogen production. Nano Lett. 11, 4978-4984 (2011).

35. Hwang, Y. J., Hahn, C., Liu, B. \& Yang, P. Photoelectrochemical properties of $\mathrm{TiO}_{2}$ nanowire arrays: a study of the dependence on length and atomic layer deposition coating. ACS Nano 6, 5060-5069 (2012).

36. Dotan, H., Sivula, K., Gratzel, M., Rothschild, A. \& Warren, S. C. Probing the photoelectrochemical properties of hematite $\left(\alpha-\mathrm{Fe}_{2} \mathrm{O}_{3}\right)$ electrodes using hydrogen peroxide as a hole scavenger. Energy Environ. Sci. 4, 958-964 (2011)

37. Di Valentin, C. et al. Adsorption of Water on reconstructed rutile $\mathrm{TiO}_{2}(011)-(2 \times 1)$ : $\mathrm{TiO}$ double bonds and surface reactivity. J. Am. Chem. Soc 127, 9895-9903 (2005)

38. Wilson, J. N. \& Idriss, H. Effect of surface reconstruction of $\mathrm{TiO}_{2}(001)$ single crystal on the photoreaction of acetic acid. J. Catalysis 214, 46-52 (2003).

39. García-Mota, M. et al. Tailoring the activity for oxygen evolution electrocatalysis on rutile $\mathrm{TiO}_{2}(110)$ by transition-metal substitution. ChemCatChem 3, 1607-1611 (2011).

40. Saison, T. et al. $\mathrm{Bi}_{2} \mathrm{O}_{3}, \mathrm{BiVO}_{4}$, and $\mathrm{Bi}_{2} \mathrm{WO}_{6}$ : impact of surface properties on photocatalytic activity under visible light. J. Phys. Chem. C 115, 5657-5666 (2011).

41. Gomathi Devi, L., Narasimha Murthy, B. \& Girish Kumar, S. Heterogeneous photo catalytic degradation of anionic and cationic dyes over $\mathrm{TiO}_{2}$ and $\mathrm{TiO}_{2}$ doped with $\mathrm{Mo}^{6+}$ ions under solar light: Correlation of dye structure and its adsorptive tendency on the degradation rate. Chemosphere 76, 1163-1166 (2009).

42. Itakura, M., Niizeki, N., Toyoda, H. \& Iwasaki, H. Hall effect and thermoelectric power in semiconductive $\mathrm{TiO}_{2}$. Jpn. J. Appl. Phys. 6, 311-317 (1967).

43. Feng, Y., Cho, I. S., Rao, P. M., Cai, L. \& Zheng, X. Sol-flame synthesis: a general strategy to decorate nanowires with metal oxide/noble metal nanoparticles. Nano Lett. 13, 855-860 (2012). 
44. Feng, Y., Cho, I. S., Cai, L., Rao, P. M. \& Zheng, X. Sol-flame synthesis of hybrid metal oxide nanowires. Proc. Combustion Inst. 34, 2179-2186 (2013).

45. Lee, C. H., Kim, D. R. \& Zheng, X. Orientation-controlled alignment of axially modulated pn silicon nanowires. Nano Lett. 10, 5116-5122 (2010).

46. Chen, R. S., Chen, C. A., Wang, W. C., Tsai, H. Y. \& Huang, Y. S. Transport properties in single-crystalline rutile $\mathrm{TiO}_{2}$ nanorods. Appl. Phys. Lett. 99, 222107-222109 (2011).

\section{Acknowledgements}

This material is based upon work supported by the Center on Nanostructuring for Efficient Energy Conversion, an Energy Frontier Research Center funded by the US Department of Energy, Office of Science, Office of Basic Energy Sciences under Award Number DE-SC0001060. Part of this research was conducted using the Cameca NanoSIMS 50L, supported by the NSF under award no. ECCS-0922648. I.S.C was supported from the National Research Foundation of Korea Grant funded by the Korean Government (Ministry of Education, Science and Technology) (NRF-2010-357-D00126).

\section{Author contributions}

I.S.C. and X.Z. designed the experiments. I.S.C., C.H.L., Y.F., M.L., P.M.R., L.C., D.R.K., R.S. and X.Z. performed experiments and analysed the data. I.S.C. and X.Z. wrote the manuscript, and all authors discussed the results and commented on the manuscript.

\section{Additional information}

Supplementary Information accompanies this paper at http://www.nature.com/ naturecommunications

Competing financial interests: The authors declare no competing financial interests.

Reprints and permission information is available online at http://npg.nature.com/ reprintsandpermissions/

How to cite this article: Cho, I. S. et al. Codoping titanium dioxide nanowires with tungsten and carbon for enhanced photoelectrochemical performance. Nat. Commun. 4:1723 doi: 10.1038/ncomms2729 (2013). 


\title{
Erratum: Codoping titanium dioxide nanowires with tungsten and carbon for enhanced photoelectrochemical performance
}

\author{
In Sun Cho, Chi Hwan Lee, Yunzhe Feng, Manca Logar, Pratap M. Rao, Lili Cai, Dong Rip Kim, \\ Robert Sinclair \& Xiaolin Zheng
}

Nature Communications 4:1723 doi: 10.1038/ncomms2729 (2013); Published 16 Apr 2013; Updated 31 Jan 2014

This Article contains errors in Figs 4 and 5 that were introduced during the production process.

In Fig. $4 c$, the $y$ axis should have been labelled ' $\eta_{\text {transport }}(\%)$ '. In addition, the figure caption for panel b should have read 'Charge transfer efficiencies' and that of panel c 'Charge transport efficiencies', instead of the converse. In Fig. 5h, the $y$ axis should have been labelled ' $\eta_{\text {transfer }}(\%)$ '. In addition, the figure caption for panel g should have read 'charge transport efficiency' and that of panel $h$ 'charge transfer efficiency', instead of the converse. Corrected versions of both figures and their legends appear below.
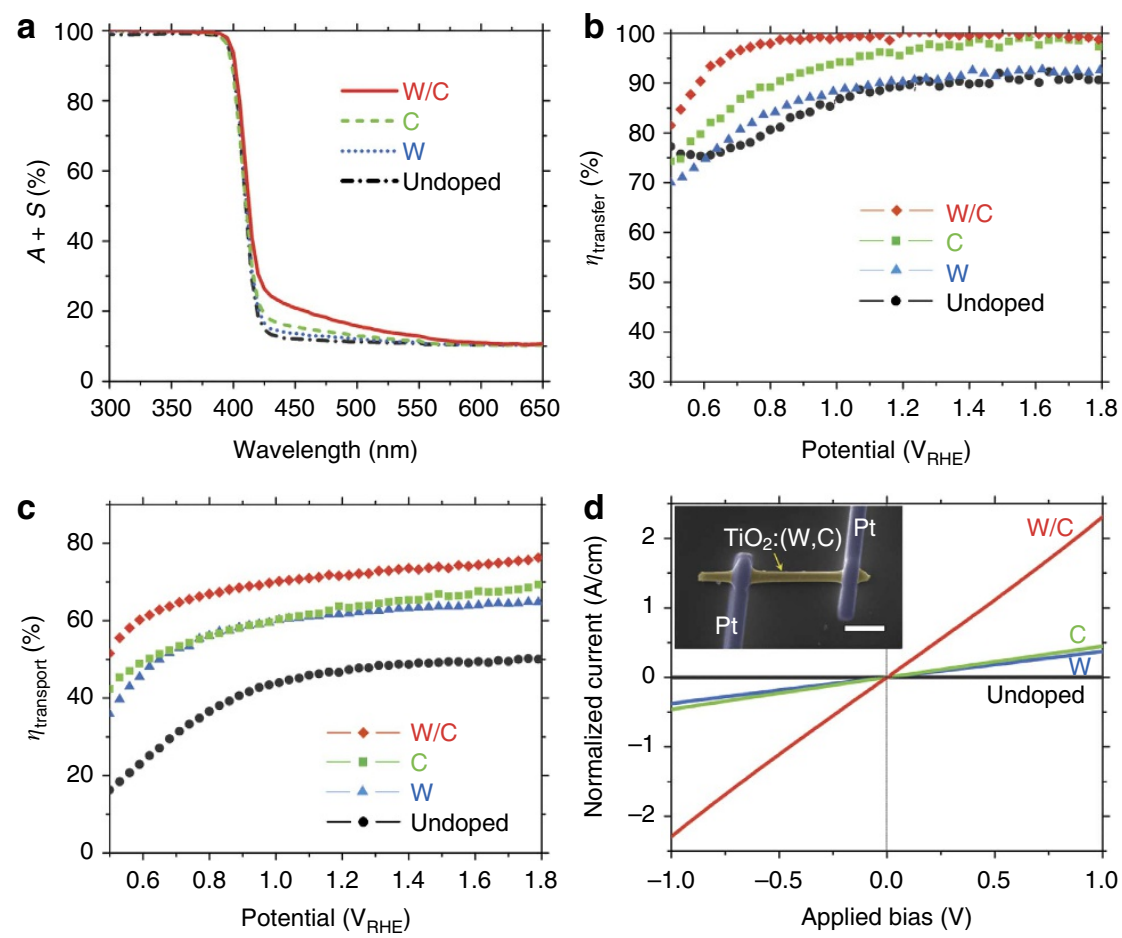

Figure 4 | Comparison of optical, charge transport and charge transfer properties. (a) Light absorption (plus scattering) of undoped (black), W-doped (blue), C-doped (green) and (W, C)-codoped $\mathrm{TiO}_{2} \mathrm{NW}$ (red) arrays grown on quartz. The integrated light absorption (plus scattering) values calculated by integrating over the wavelength are 59.5\%,60.7\%, 61.1\% and 64.0\% for undoped, W-doped, C-doped and (W, C)-codoped $\mathrm{TiO}_{2} \mathrm{NWs \text {, }}$ respectively. (b) Charge transfer efficiencies. (c) Charge transport efficiencies. (d) Current-voltage curves of single NW. The inset shows the scanning electron microscopy image of single $\mathrm{TiO}_{2}:(\mathrm{W}, \mathrm{C}) \mathrm{NW}$ with metal $(\mathrm{Pt})$ contacts at both ends. Scale bar, $1 \mu \mathrm{m}$. 
a

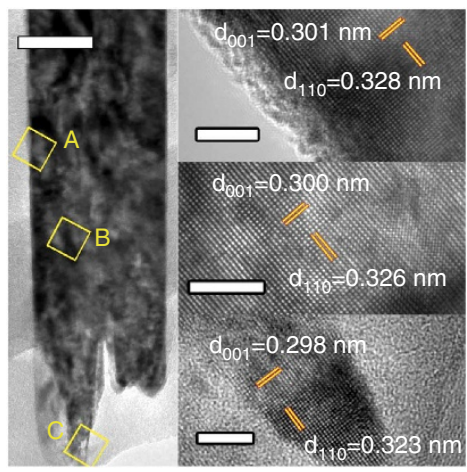

b

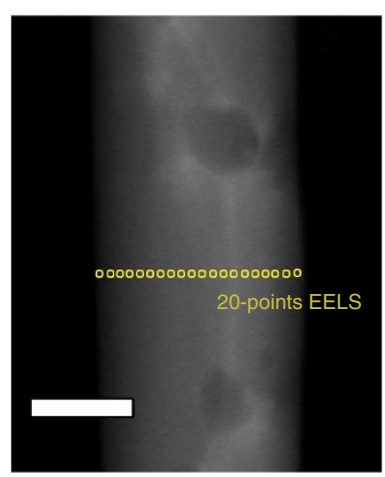

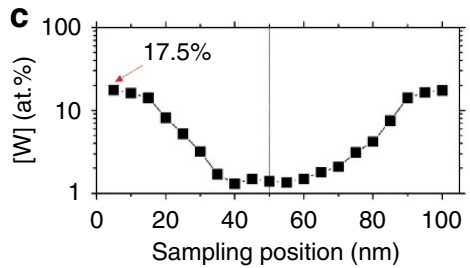

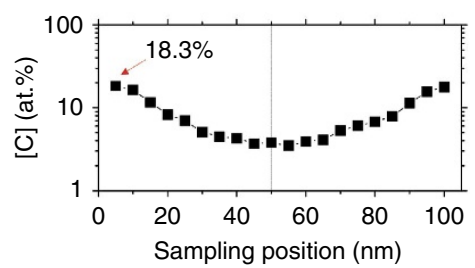

d

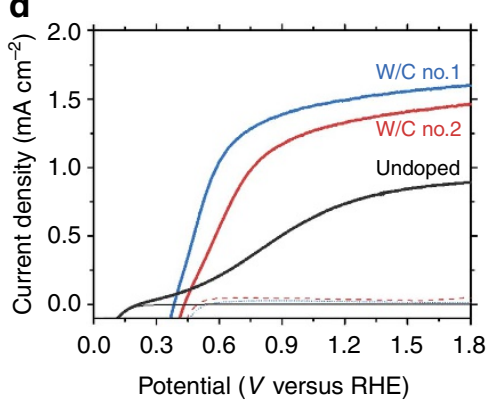

e

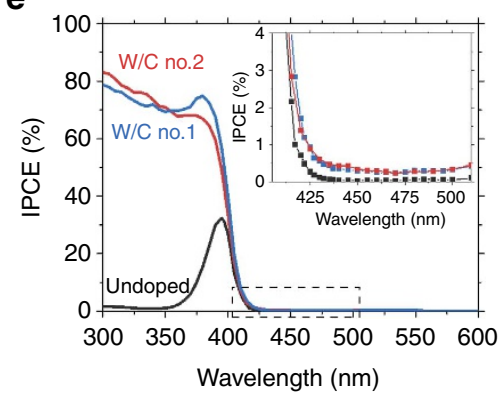

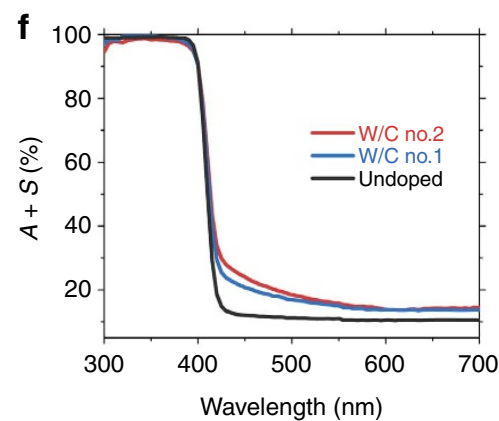
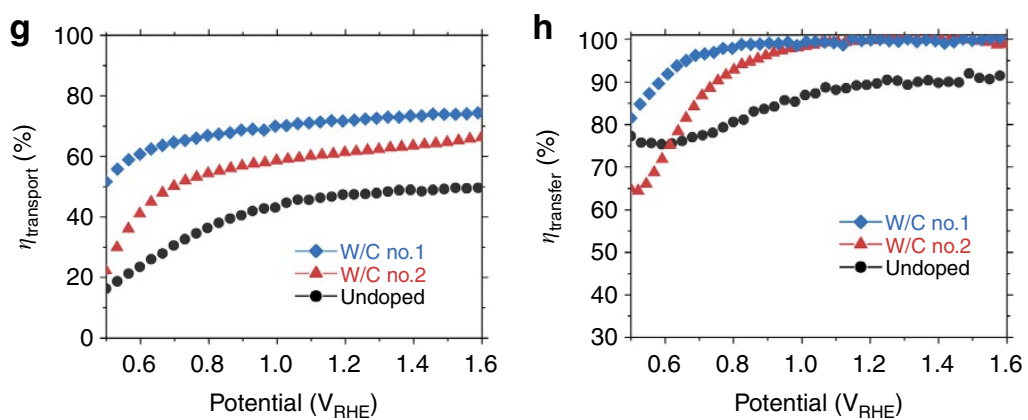

Figure 5 | Characterization and PEC water-splitting performance of NWs with high $\mathbf{W}$ - and C-doping concentrations. (a) TEM and high-resolution TEM images of W/C no. 2 (W: 17.5 at.\%, C: 18.3 at.\% at the NW surface). Scale bar, $50 \mathrm{~nm}$ (TEM) and 5 nm (high-resolution TEM). (b) STEM image. Scale bar, $50 \mathrm{~nm}$. (c) Concentration profiles of $\mathrm{W}$ and $\mathrm{C}$ dopants along the NW diameter in W/C no. 2. Comparison of W/C no. 1 (blue) and W/C no. 2 (red) with (d) three electrodes J-V curves (W/C no. 1, W: 10.2 at.\%, C: 13.1 at.\% at the NW surface). (e) IPCE, (f) light absorption (quartz substrate), $(\mathbf{g})$ charge transport efficiency and $(\mathbf{h})$ charge transfer efficiency. The data of undoped $\mathrm{TiO}_{2} \mathrm{NWs}$ (black) are added for reference. 